\title{
Editorial
}

\section{Vitamin D and Public Health}

\author{
David Scott ${ }^{1,2, *(1)}$ and Peter R. Ebeling ${ }^{1}$ \\ 1 Department of Medicine, School of Clinical Sciences at Monash Health, Monash University, Clayton, \\ Victoria 3168, Australia; peter.ebeling@monash.edu \\ 2 Department of Medicine and Australian Institute of Musculoskeletal Science, Melbourne Medical \\ School-Western Campus, The University of Melbourne, St. Albans, Victoria 3121, Australia \\ * Correspondence: david.scott@monash.edu
}

Received: 4 March 2019; Accepted: 5 March 2019; Published: 8 March 2019

Since the early 2000's, interest in vitamin D has grown significantly among the research, clinical and lay communities. This has resulted in exponential increases in research outputs, clinical testing of vitamin D status, and availability of vitamin D supplements and fortified foods [1]. Despite this, vitamin D deficiency remains an important global public health issue, prevalent across many countries, cultures, and age groups [2]. There does, however, remain significant controversy regarding vitamin D, with insufficient evidence currently available to support a need for routine screening, or to explain its role in maintaining non-skeletal health [3]. Thus, as further research is required to achieve consensus on the role of vitamin $\mathrm{D}$ in public health, we were motivated to contribute to the scientific discourse through this Special Issue of the International Journal of Environmental Research and Public Health.

In this Special Issue, a systematic review by Heath et al. provided up-to-date evidence on the relationship between vitamin $\mathrm{D}$ and mortality. The authors concluded that 25 -hydroxyvitamin D $(25(\mathrm{OH}) \mathrm{D})$ concentrations (up to a certain threshold) are associated with all-cause mortality, with limited evidence on their effect on cardiovascular mortality, but potential moderate effects on deaths due to respiratory diseases and cancer [4]. In support of these findings, a randomised controlled trial in Taekwondo athletes reported that increases in $25(\mathrm{OH}) \mathrm{D}$ concentrations in response to vitamin D supplementation are associated with reductions in upper respiratory tract infections during winter [5]. On the other hand, a separate review indicated that the current evidence from human studies does not support a role of vitamin $\mathrm{D}$ in reducing incidence of cancer, despite its potential benefit for cancer mortality and pre-clinical studies demonstrating that vitamin D may prevent carcinogenesis, tumour invasiveness and metastases [6]. Similarly, patients with chronic kidney disease who have adequate vitamin $\mathrm{D}$ concentrations appear to have a better prognosis for several outcomes including mortality, but the mechanisms for these effects are unclear and currently there is a lack of randomised controlled trials to support guidelines for prescribing vitamin D in this population [7]. Clearly, further research is required to determine how low vitamin $\mathrm{D}$ concentrations contribute to increased prevalence of some non-skeletal diseases, to rule out reverse causality as an explanation, and to elucidate the mechanisms by which they influence prognosis.

Amongst non-skeletal effects of vitamin D, improvements in physical function have been amongst the most widely investigated, particularly in older adult populations. Our observational study presented evidence that low vitamin D status is common in overweight and obese older adults and also associated with poor quadriceps strength and lower-limb muscle power in women [8]. Observations such as this have led to numerous studies into the role of vitamin D supplementation for improving physical function and cardiometabolic health in older adults. A trial presented here provided preliminary evidence that vitamin D supplementation during an exercise program can reduce homocysteine (an amino acid linked with an increased risk of cardiovascular disease) concentrations in older women, although there was a lack of effect of vitamin D supplementation alone, 
which is consistent with evidence that exercise is more beneficial than vitamin D supplementation for cardiovascular health [9].

There is also substantial interest in vitamin $\mathrm{D}$ and women and children's health as evidenced by several articles addressing this topic in this Special Issue. While it is currently unclear whether vitamin D supplementation improves fertility or pregnancy outcomes, vitamin D deficiency is common in pregnant and lactating women and supplementation may improve vitamin $\mathrm{D}$ and calcium status in the mother, foetus and infant [10]. From the Australian perspective, the review by Di Marco et al. highlighted that while cases of nutritional rickets are rare, children of newly-arrived immigrants in particular may be at increased risk, and so vitamin D deficiency remains a concern, even in a country with relatively high levels of sun exposure [11]. This was supported by an original research study of pre-school children in southern Croatia which observed that over half the study population had low $25(\mathrm{OH}) \mathrm{D}$ concentrations (with girls at a greater risk compared with boys), despite the high sun exposure levels in this region [12].

A significant challenge to improving vitamin D status on the population level is addressing poor knowledge and/or indifferent attitudes. Amongst UK adults, only half expressed concerns regarding their vitamin D concentrations, but over $80 \%$ wanted to learn more about vitamin D. Importantly, greater concern and knowledge predicted increased likelihood of vitamin D supplement use, while participants residing in England were three times less likely to be taking vitamin D compared with those in Scotland [13]. Similar findings were reported in a survey of Polish mothers; maternal education levels were significant predictors of knowledge about vitamin D and likelihood of using supplements [14]. Education and public health messaging are, therefore, key to ensuring individuals take steps to monitor and address their vitamin D status and that of their children. Finally, one of the most potentially effective strategies to improve the vitamin D status of populations is food fortification. Kiely and Cashman provided a compelling summary of the ODIN project, including almost 56,000 EU residents, reporting evidence that fortification strategies could safely increase intakes of vitamin $\mathrm{D}$ and prevent low $25(\mathrm{OH}) \mathrm{D}$ concentrations in a range of population sub-groups, including those at greatest risk [15].

In summary, this Special Issue demonstrated that low vitamin D concentrations are prevalent across populations and associated with increased mortality, reduced physical function, and poor prognosis for a variety of chronic disease conditions. Further research is required, however, to determine whether low vitamin D itself is a causative factor in these outcomes. Regardless, given its known benefits for skeletal health, particularly in children, future studies should explore methods for delivering education and food-fortification to a range of culturally and ethnically diverse populations in order to reduce the high prevalence of vitamin D deficiency worldwide.

Author Contributions: D.S. drafted the original manuscript and P.R.E. revised the manuscript.

Funding: This research received no external funding.

Conflicts of Interest: The authors declare no conflict of interest.

\section{References}

1. Cashman, K.D.; Dowling, K.G.; Škrabáková, Z.; Gonzalez-Gross, M.; Valtueña, J.; De Henauw, S.; Moreno, L.; Damsgaard, C.T.; Michaelsen, K.F.; Mølgaard, C.; et al. Vitamin D deficiency in Europe: Pandemic? Am. J. Clin. Nutr. 2016, 103, 1033-1044. [CrossRef] [PubMed]

2. Palacios, C.; Gonzalez, L. Is vitamin d deficiency a major global public health problem? J. Steroid Biochem. Mol. Biol. 2014, 144, 138-145. [CrossRef] [PubMed]

3. Manson, J.E.; Bassuk, S.S. Vitamin d research and clinical practice: At a crossroadsvitamin D research and clinical practicevitamin d research and clinical practice. JAMA 2015, 313, 1311-1312. [CrossRef] [PubMed]

4. Heath, A.K.; Kim, I.Y.; Hodge, A.M.; English, D.R.; Muller, D.C. Vitamin D status and mortality: A systematic review of observational studies. Int. J. Environ. Res. Public Health 2019, 16, 383. [CrossRef] [PubMed] 
5. Jung, H.C.; Seo, M.-W.; Lee, S.; Kim, S.W.; Song, J.K. Vitamin D3 supplementation reduces the symptoms of upper respiratory tract infection during winter training in vitamin d-insufficient taekwondo athletes: A randomized controlled trial. Int. J. Environ. Res. Public Health 2018, 15, 2003. [CrossRef] [PubMed]

6. Minisola, S.; Ferrone, F.; Danese, V.; Cecchetti, V.; Pepe, J.; Cipriani, C.; Colangelo, L. Controversies surrounding vitamin D: Focus on supplementation and cancer. Int. J. Environ. Res. Public Health 2019, 16, 189. [CrossRef] [PubMed]

7. Franca Gois, P.H.; Wolley, M.; Ranganathan, D.; Seguro, A.C. Vitamin d deficiency in chronic kidney disease: Recent evidence and controversies. Int. J. Environ. Res. Public Health 2018, 15, 1773. [CrossRef] [PubMed]

8. Dang, M.; Shore-Lorenti, C.; McMillan, L.B.; Mesinovic, J.; Hayes, A.; Ebeling, P.R.; Scott, D. Associations of serum 25-hydroxyvitamin D with physical performance and bone health in overweight and obese older adults. Int. J. Environ. Res. Public Health 2019, 16, 509. [CrossRef] [PubMed]

9. Walentukiewicz, A.; Lysak-Radomska, A.; Jaworska, J.; Prusik, K.; Prusik, K.; Kortas, J.A.; Lipiński, M.; Babinska, A.; Antosiewicz, J.; Ziemann, E. Vitamin D supplementation and nordic walking training decreases serum homocysteine and ferritin in elderly women. Int. J. Environ. Res. Public Health 2018, 15, 2064. [CrossRef] [PubMed]

10. Pilz, S.; Zittermann, A.; Obeid, R.; Hahn, A.; Pludowski, P.; Trummer, C.; Lerchbaum, E.; Pérez-López, F.R.; Karras, S.N.; März, W. The role of vitamin d in fertility and during pregnancy and lactation: A review of clinical data. Int. J. Environ. Res. Public Health 2018, 15, 2241. [CrossRef] [PubMed]

11. Di Marco, N.; Kaufman, J.; Rodda, C.P. Shedding light on vitamin d status and its complexities during pregnancy, infancy and childhood: An australian perspective. Int. J. Environ. Res. Public Health 2019, 16, 538. [CrossRef] [PubMed]

12. Karin, Z.; Gilic, B.; Supe Domic, D.; Sarac, Z.; Ercegovic, K.; Zenic, N.; Uljevic, O.; Peric, M.; Markic, J. Vitamin D status and analysis of specific correlates in preschool children: A cross-sectional study in southern croatia. Int. J. Environ. Res. Public Health 2018, 15, 2503. [CrossRef] [PubMed]

13. O'Connor, C.; Glatt, D.; White, L.; Revuelta Iniesta, R. Knowledge, attitudes and perceptions towards vitamin D in a UK adult population: A cross-sectional study. Int. J. Environ. Res. Public Health 2018, 15, 2387. [CrossRef] [PubMed]

14. Zadka, K.; Pałkowska-Goździk, E.; Rosołowska-Huszcz, D. The state of knowledge about nutrition sources of vitamin $\mathrm{D}$, its role in the human body, and necessity of supplementation among parents in central poland. Int. J. Environ. Res. Public Health 2018, 15, 1489. [CrossRef] [PubMed]

15. Kiely, M.; Cashman, K.D. Summary outcomes of the odin project on food fortification for vitamin D deficiency prevention. Int. J. Environ. Res. Public Health 2018, 15, 2342. [CrossRef] [PubMed] 